\title{
Commentary: In a heart of stone beats a muscle of pure flint
}

\author{
Tomasz A. Timek, MD, PhD
}

Surgical septal myectomy has become the gold standard treatment of symptomatic left ventricular outflow obstruction (LVOT) associated with hypertrophic cardiomyopathy (HCM). ${ }^{1}$ The procedure reliably provides resolution of symptoms, reduction in mitral regurgitation, and normalization of life expectancy. ${ }^{2}$ Less attention has been focused on more subtle clinical end points such as cardiac chamber remodeling and myocardial fibrosis. Tang and colleagues ${ }^{3}$ present a large cohort of patients who underwent surgical myectomy for obstructive HCM with 57 patients having follow-up magnetic resonance imaging (MRI). The authors found that septal myectomy positively influenced left atrial and ventricular remodeling but could not halt progressive myocardial fibrosis.

In 507 patients who had pre- and postoperative echocardiography, left atrial diameter decreased significantly from 43 to $40 \mathrm{~mm}$, whereas the proportion of moderate or severe mitral regurgitation decreased from $65.3 \%$ to $4.9 \%$. It is tempting to speculate that atrial remodeling is a surrogate for reduction in mitral insufficiency-which is well described with adequate septal myectomy. It would be interesting to ascertain whether atrial size was altered in the 25 patients who had persistent moderate or greater mitral regurgitation after the surgical procedure. Furthermore, 65 patients had a history of atrial fibrillation with 23 undergoing a maze procedure. Although this number is relatively small among the study group, reestablishment of sinus rhythm could further facilitate left

\footnotetext{
From the Division of Cardiothoracic Surgery, Spectrum Health, and Michigan State University College of Human Medicine, Grand Rapids, Mich.

Disclosures: The author reported no conflicts of interest.

The Journal policy requires editors and reviewers to disclose conflicts of interest and to decline handling or reviewing manuscripts for which they may have a conflict of interest. The editors and reviewers of this article have no conflicts of interest.

Received for publication July 8, 2020; revisions received July 8, 2020; accepted for publication July 10, 2020; available ahead of print July 15, 2020.

Address for reprints: Tomasz A. Timek, MD, PhD, Division of Cardiothoracic Surgery, Spectrum Health, and Michigan State University College of Human Medicine, 100 Michigan Ave NE, Grand Rapids, MI 49503 (E-mail: tomasz.timek@ spectrumhealth.org).

J Thorac Cardiovasc Surg 2022;163:1836-7

$0022-5223 / \$ 36.00$

Copyright (c) 2020 by The American Association for Thoracic Surgery

https://doi.org/10.1016/j.jtcvs.2020.07.035
}

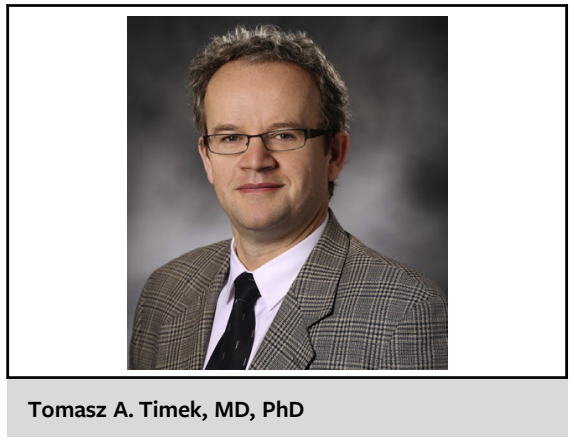

CENTRAL MESSAGE

Septal myectomy may induce positive chamber remodeling in

HCM patients, but it does not halt myocardial fibrosis.

atrial remodeling. The presented clinical cohort is reflective of advanced HCM disease with mean maximal septal thickness of $23 \mathrm{~mm}$ and a mean gradient of $77 \mathrm{~mm} \mathrm{Hg}$. Although the mass of removed muscle was not provided in this study, the historical weight of myectomy specimen at Fuwai hospital is $9 \pm 6 \mathrm{~g}$, which is less than the postoperative LV mass regression observed by MRI (166.8 $\mathrm{g}$ to $149.3 \mathrm{~g})$. In conjunction with reduced posterior wall thickness, these data suggest true postmyectomy chamber remodeling possibly from reduction of intracardiac pressure or an intrinsic myocardial process. Echocardiographically measured LV end-diastolic diameter increased significantly after myectomy, although LV volume was unchanged in the 57 patients who underwent pre- and postoperative MRI. Larger chamber size may represent another manifestation of regressing LV hypertrophy with potential improvement in luisotropic properties of the myocardium. Perhaps the most significant finding of the study is that which is not intuitive. MRI late gadolinium enhancement (LGE), a reflection of myocardial fibrosis, progressed after myectomy suggesting that surgical resection can reverse the hemodynamic burden of LVOT obstruction, yet the pathological myocardial processes at the core of the disease remains unhalted. Whether this progression is a reflection of advanced obstructive $\mathrm{HCM}$ $(15.2 \% \pm 9.6 \%$ LGE pre-myectomy) that if treated earlier may indeed be attenuated remains to be studied as the percentage of LGE in most series is lower than currently reported. However, LGE $>15 \%$ has been shown to be associated with higher rates of sudden death in 
obstructive HCM patients even after surgical myectomy. ${ }^{4}$ As advised by the authors, these patients need close surveillance and possible device implantation.

The study by Tang and colleagues ${ }^{3}$ demonstrates again that septal myectomy is very effective in treating LVOT obstruction associated with HCM and may have additional benefits of reversing ventricular and atrial chamber remodeling, but continued progression of myocardial fibrosis is of concern. However, adjunctive medical therapy appears to be on the horizon. Mavacamten (MYK-461), a reversible inhibitor of cardiac-specific myosin, has been shown to suppress development of ventricular hypertrophy, cardiomyocyte disarray, and attenuate hypertrophic and profibrotic gene expression in mice with $\mathrm{HCM}^{5}$ Early clinical trials reveal promising results. ${ }^{6,7}$ Much remains to be learned, but it appears that surgical myectomy and innovative pharmacotherapy may offer the best hope to completely treat the heart of stone.

\section{References}

1. Kotkar Kd, Said SM, Dearani JA, Schaff HV. Hypertrophic obstructive cardiomyopathy: the Mayo Clinic experience. Ann Cardiothorac Surg. 2017;6: 329-36.

2. Ommem SR, Maron BJ, Olivotto I, Maron MS, Cecchi F, Betocchi S, et al. Longterm effects of surgical septal myectomy on survival in patients with obstructive hypertrophic cardiomyopathy. J Am Coll Cardiol. 2005;46:470-6.

3. Tang B, Song Y, Yang Q, Cui H, Ji K, Zhao S, et al. Changes in left atrial function, left ventricle remodeling, and fibrosis after septal myectomy for obstructive hypertrophic cardiomyopathy. J Thorac Cardiovas Surg. 2022;163:1828-34.e4.

4. Mentias A, Raeisi-Giglou P, Smedira NG, Feng K, Sato K, Wazni O, et al. Late gadolinium enhancement in patients with hypertrophic cardiomyopathy and preserved systolic function. J Am Coll Cardiol. 2018;72:857-70.

5. Green EM, Wakimoto H, Anderson RL, Evanchik MJ, Gorham JM, Harrison BC, et al. A small-molecule inhibitor of sarcomere contractility suppresses hypertrophic cardiomyopathy in mice. Science. 2016;351:617-21.

6. Heitner SB, Jacoby D, Lester SJ, Owens A, Wang A, Zhang D, et al. Mavacamten treatment for obstructive hypertrophic cardiomyopathy: a clinical trial. Ann Intern Med. 2019;170:741-8

7. Ho CY, Mealiffe ME, Bach RG, Bhattacharya M, Choudhury L, Edelberg JM, et al. Evaluation of mavacamten in symptomatic patients with nonobstructive hypertrophic cardiomyopathy. J Am Coll Cardiol. 2020;75:2649-60.

\section{See Article page 1828.}

\section{Commentary: Left heart remodeling with septal myectomy: Fibrosis is a relative but not absolute concern}

\author{
David Blitzer, MD, ${ }^{\mathrm{a}}$ Shepard D. Weiner, MD, ${ }^{\mathrm{b}}$ \\ Stephanie N. Nguyen, MD, ${ }^{a}$ and \\ Hiroo Takayama, MD, $\mathrm{PhD}^{\mathrm{a}}$
}

In this issue of the Journal, Tang and colleagues ${ }^{1}$ provide surgeons with important perspectives beyond septal

\footnotetext{
From the ${ }^{\mathrm{a} D i v i s i o n}$ of Cardiothoracic Surgery, Department of Surgery, and ${ }^{\mathrm{b}}$ Division of Cardiology, Department of Medicine, Columbia University Medical Center, New York, NY

Disclosures: The authors reported no conflicts of interest.

The Journal policy requires editors and reviewers to disclose conflicts of interest and to decline handling or reviewing manuscripts for which they may have a conflict of interest. The editors and reviewers of this article have no conflicts of interest.

Received for publication July 11, 2020; revisions received July 11, 2020; accepted for publication July 13, 2020; available ahead of print July 16, 2020.

Address for reprints: Hiroo Takayama, MD, PhD, Division of Cardiothoracic Surgery, Department of Surgery, Columbia University Medical Center, 177 Fort Washington Ave, New York, NY 10032 (E-mail: ht2225@cumc.columbia.edu).

J Thorac Cardiovasc Surg 2022;163:1837-8

$0022-5223 / \$ 36.00$

Copyright (c) 2020 by The American Association for Thoracic Surgery

https://doi.org/10.1016/j.jtcvs.2020.07.044
}

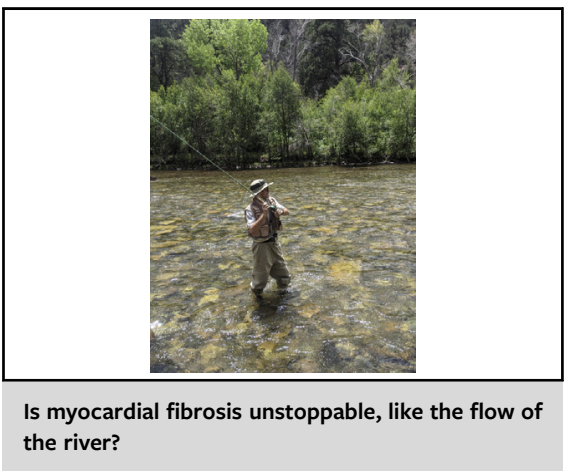

CENTRAL MESSAGE

Septal myectomy may stop the progression of myocardial fibrosis, but it does not prompt regression of fibrotic segments.

thickness and left ventricular outflow tract gradient for obstructive hypertrophic cardiomyopathy (HCM). They analyzed the anatomic and functional changes of the left heart after septal myectomy (SM) by retrospectively reviewing imaging studies obtained before and after surgery. Their results corroborate previously published data: decreased left ventricular outflow tract gradient, left atrial diameter, left ventricular ejection fraction, and wall thickness after SM. ${ }^{1-3}$ 